\title{
Communication and Self-Efficacy Competency of Nurses in Emergency Departments: A Multicenter Study
}

\author{
Tahereh Najafi Ghezeljeh ${ }^{1}$, Soudabeh Jafari ${ }^{2}$, Shima Haghani ${ }^{3}$
}

\begin{abstract}
Background \& Aims: The emergency department is one of the most important wards in a hospital, and its functions can have a great impact on the activities of other wards. In the emergency department, 24- hour emergency services are provided to patients, and there is a large number of patients in this ward, which shows the importance of good performance and effective communication of nurses to maintain patient safety and provide quality care. Effective communication is one of the pillars of nursing and having communication skills is a professional necessity required for all nurses especially those who work in the emergency wards to provide safe and quality care. Nurses' competent performances in the emergency wards are also affected by their selfefficacy. Thus, this study was conducted to determine the communication s and self-efficacy competency of nurses.
\end{abstract}

Materials \& Methods: This descriptive cross-sectional study was carried out in the emergency wards of hospitals affiliated to Iran University of Medical Sciences in 2020. In this study, 234 nurses were selected through census method and based on the inclusion criteria and were evaluated using Communication Competence and Self-Efficacy Scales. The Communication Competence Scale consisted of 35 questions on a five-point Likert scale, ranging from strongly agree (5) to strongly disagree (1). The overall score of the communication competence scale was 35-175, with the higher scores indicating high communicative competence. The Communication Self-Efficacy Scale consisted of 12 items on a 10- point scale ranging from not at all sure (1) to very clear (10). The overall scores of the communication self-efficacy scale were 12-120, with high values indicating higher communication self-efficacy. Data were analyzed using independent t-test, one-way ANOVA, Pearson's correlation-coefficient, and linear regression in SPSS version 16.

Results: In total, 234 nurses working in emergency departments participated in this study. The response rate of the participants was $100 \%$. According to the results, the mean score of the nurses' communication competency was $141.03 \pm 15.09$, which was higher than the average value (108). The highest average communication competencies related to "let others know that you understand them", "listen to what people say" and "support others" were $4.15 \pm 0.70,4.15 \pm 57$, and $4.15 \pm 0.68$. The lowest mean belonged to the item "you do not pay attention to meeting and talking with strangers" $(2.32 \pm 1.28)$. The mean score of emergency nurses' communication self-efficacy was $86.24 \pm 22.00$ that was slightly higher than the average point (66). The highest average communication self-efficacy was related to "Have appropriate nonverbal behaviors (such as eye contact, facial expressions, and gestures) during conversation $(7.84 \pm 2.15)$. And the lowest average belonged to the item "Have a plan prepared in advance to talk to the patients. Based on the results of the regression model, $11 \%$ of communication competency among emergency nurses were explained by working hours per week $(\mathrm{P}=0.001)$, hospital type $(\mathrm{P}<0.001)$ and education level $(\mathrm{P}=0.023)$, and working hours per week with the standard coefficient of -0.249 had the most effect on nurses' communication competencies. Based on the mean and standard deviation, the nurses' communication self-efficacy score was $86.24 \pm 22.00$, which was higher than the average (66). Also, only 12 percent of nurses' communication self-efficacy was explained by independent variables (demographic variables) $(\mathrm{P}<0.001)$. There was a direct linear relationship between the variables of age

\footnotetext{
1. Nursing Care Research Center, Critical care and Emergency Department, School of Nursing and Midwifery, Iran University of Medical Sciences, Tehran, Iran

2. Critical care and Emergency Department, School of Nursing and Midwifery, Iran University of Medical Sciences,

Tehran, Iran (Corresponding author) Tel: 09116901160 Email: sodabe.jafari5682@gmail.com

${ }^{3}$. Biostatistics, Nursing Care Research Center, Iran University of Medical Sciences, Tehran, Iran
} 
$(\mathrm{P}=0.035)$ and nursing experience $(\mathrm{P}=0.043)$ with nurses' communication self-efficacy and there was a statistically significant inverse relationship with working hours per week $(\mathrm{P}<0.001)$. Only working hours per week $(\mathrm{P}<0.001)$ was significant in the regression model ( tandard coefficient $=-0.37)$.

Conclusion: Although the levels of communication competencies and communication self-efficacies of the nurses in the emergency wards were approximately high, due to their activity and their role in the front line of the organization, higher levels of communication competency and self-efficacy are expected. Effective communication of health workers, especially nurses, is essential in improving the quality of care and maintaining patient safety. Due to their role, nurses should have extensive communication with patients and other health workers, so communication competence is an important principle in providing nursing care. Owing to the structure of the emergency department and the patients visiting this department, it is useful and necessary to find the cause and determine the appropriate solutions to increase the communication competency and selfefficacy of emergency nurses to the highest possible level and thus improve quality and safe care. According to the results of the present study, communication competence decreases by increasing working hours, which can be the result of fatigue and high work pressure after spending long hours in the stressful emergency department. The presence of patients in need of immediate and acute care increases fatigue, thereby leading to the low efficiency of nursing services and endangers the safety of patients. It is necessary to plan for employing experienced nurses as well as those with higher and specialized education in the emergency department. However, it will not diminish the importance of increasing the workforce in the emergency departments and reducing the workload of nurses in order to improve the quality of services and improve patient safety. Communication self-efficacy of nurses working in the emergency department was relatively high in this study. The highest communication self-efficacy of the studied nurses was related to having appropriate non-verbal behaviors during the conversation and the lowest communication self-efficacy of the nurses was related to planning to talk to the patients. Self-efficacy is considered an important indicator of a person's confidence in performance, including job performance. A strong sense of self-efficacy increases nurses' confidence in their performance and knowledge. Nurses who are confident in their abilities in all areas, including effective communication, define their goals and are committed to maintaining them.

Keywords: Communication, Competencies, Self-Efficacy, Emergency Nurses

\section{Conflict of Interest: No}

How to Cite: Najafi Ghezeljeh T, Jafari S, Haghani SH. Communication and Self-Efficacy Competency of Nurses in Emergency Departments: A Multicenter Study. Iran Journal of Nursing. 2021; 34(129): 82-95.

Received: 16 Jan 2021

Accepted: 17 Apr 2021 


\title{
شايستى و خودكار آمدى ارتباطى برستاران اورزانس: يك مطالعه جند مركزى
}

\author{
طاهره نجفى قزلجه '، سودابه جعفرى '، شيما حقانى
}

\begin{abstract}
"جكيده زمينه و هدف: يرستارى از جمله مشاغلى است كه ارتباط مؤثر از اركان آن بوده و بويزه در بخش اورزانس، داشتن شايستكى ارتباطى يك ضرورت

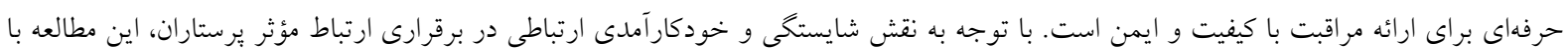

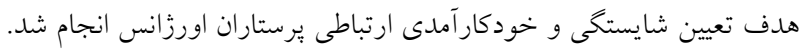

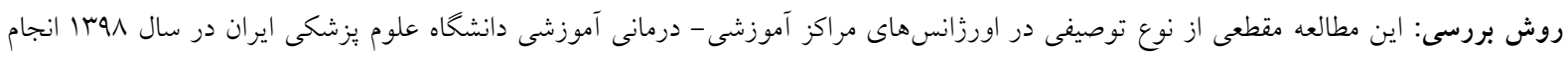

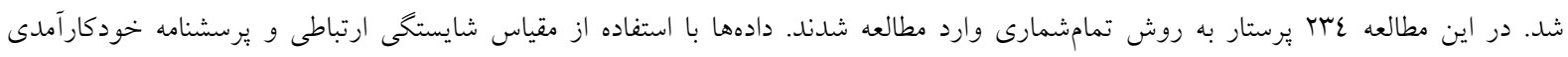

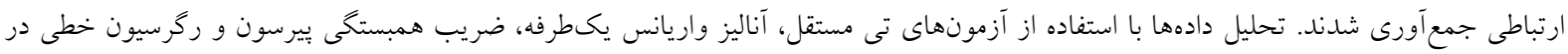

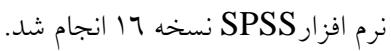

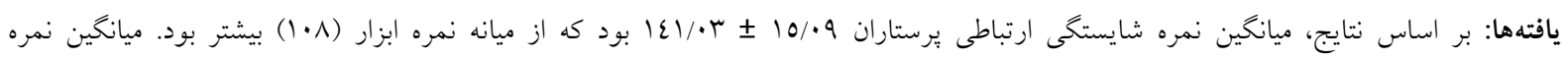

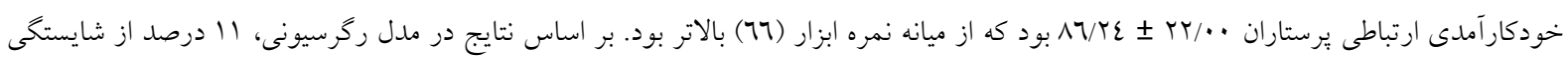

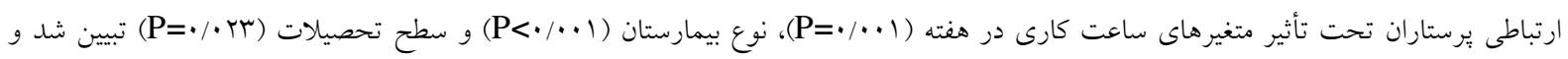

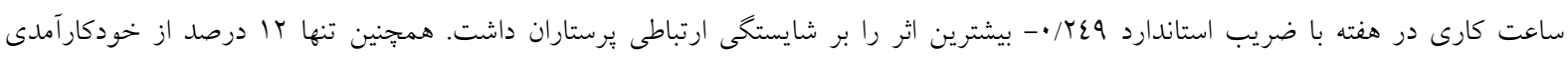
ارتباطى برستاران تحت تأثير ساعت كارى در هفته تبيين شدر.

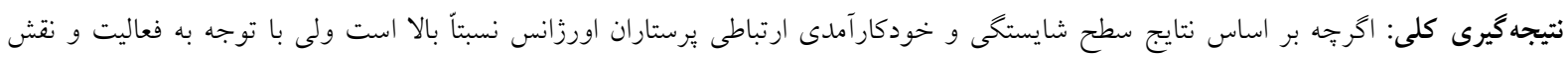

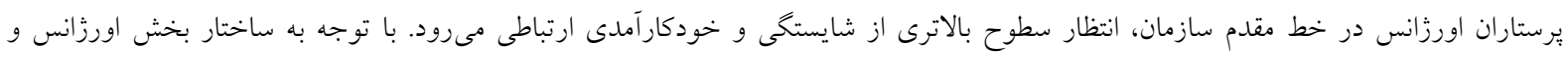

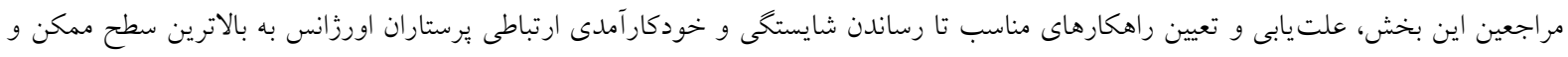

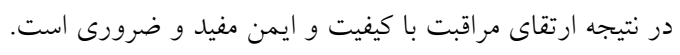

كليد وازمها: شايستخى ارتباطى، خود كار آمدى ارتباطى، برستاران اورزانس

$$
\text { تاريخ دريخ منافع: وجود ندارد. }
$$

'. مركز تحقيقات مراقبتهاى يرستارى، تروه يرستارى مراقبت ويزه و اورخانس، دانشكده يرستارى و مامايى، دانشكاه علوم يزشكى و خدمات بهداشتى درمانى ايران، تهران، ايران

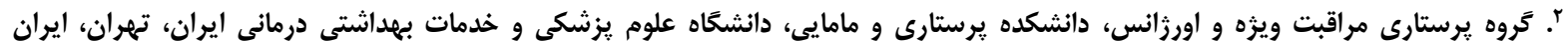

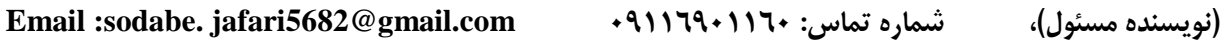

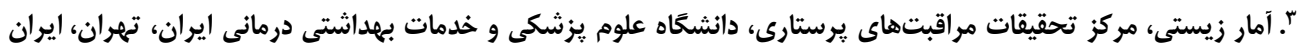


بيشخيرانه لازم و ضرورى است جرا كه شايستخى هاى ارتباطى ضعيف منجر به تهديد و اختلال در ايمنى بيمار

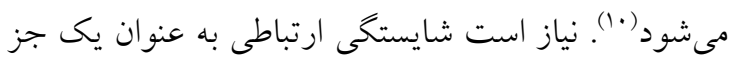

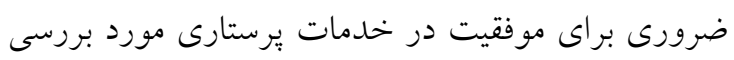
و توجه قرار كيرد بردئ.

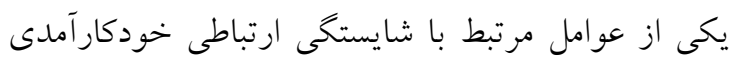

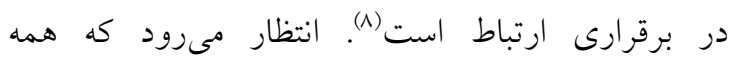

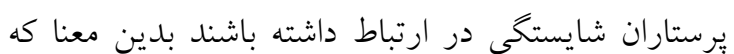
بتوانند به طور مؤثر با بيمار، خانواده و همكاران ارتباط

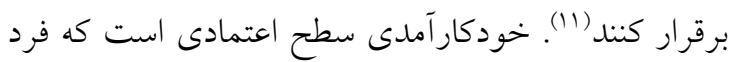
به خود به واسطه تسلط بر مهارتهاى مورد نظر دارد (r).

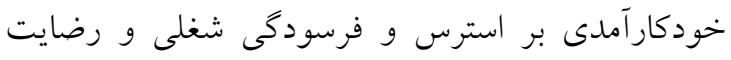
شغلى مؤثر است (rا). خودكارآمدى در خرستارى واسطه بين دانش و عمل به آن است و در بكارگيرى دانش و و ودون

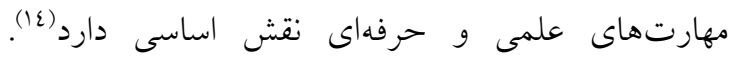
خودكارآمدى در يرستارى نشان دهنده توانايى است، شرايطى كه منعكس كننده كنترل فورى احساس بوده و و

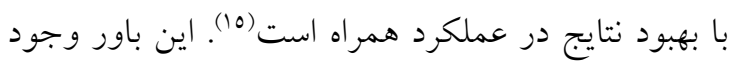

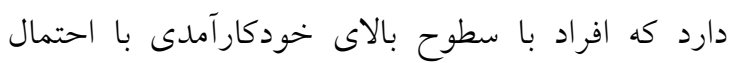

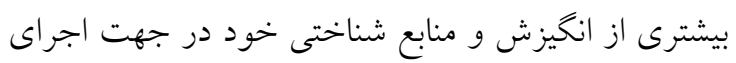

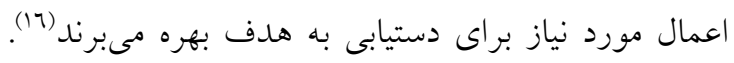

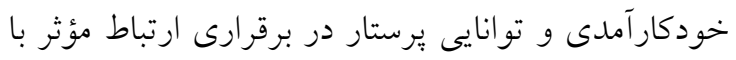

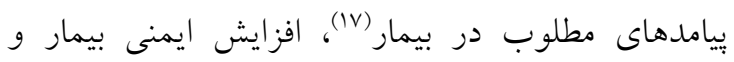
بهبود ييامدهاى مرتبط با يرستار (1) ارتباط دارد. بنابراين

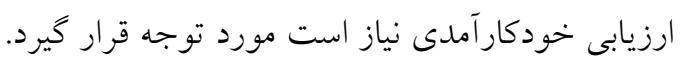

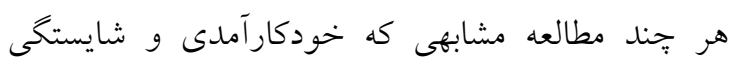
ارتباطى קرستاران اورزانس را مورد بررسى قرار دهد،

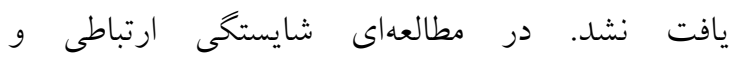
خودكارآمدى ارتباطى يرستاران اورزانس در كره جنوبى را خوب گزارش دادند و نشان دادند كه اين دو متغيير با هم مرتبط هستند و با رضايت شغلى ارتباط دارند (19). در يُزوهشى ديخر در ايران مهارتهاى ارتباطى بِرستاران با فيا

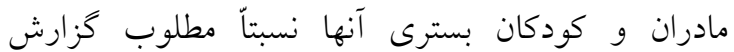

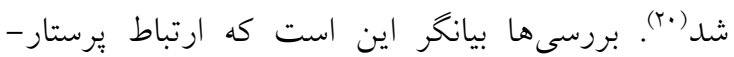

مقدمه

بخش اورزانس يكى از مهمترين بخشههاى بيمارستان

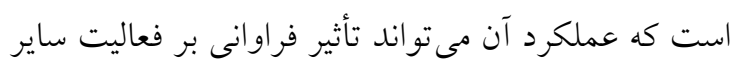

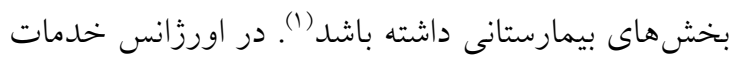

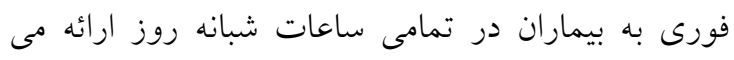
شود و حجم بالايى از مراجعين به اين بخش وجود دود دارد

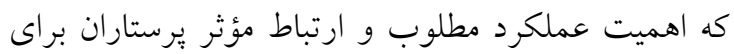

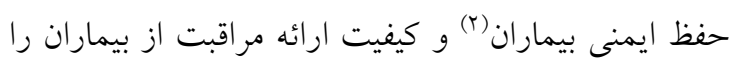

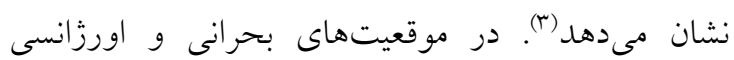

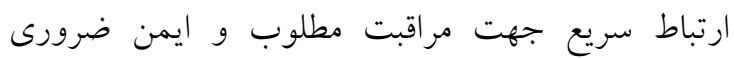

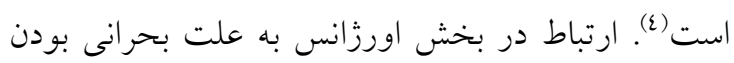

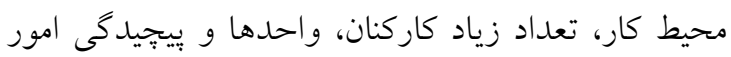
داراى اهميت خاص بوده و تضمين كننده ايمنى بيمار و

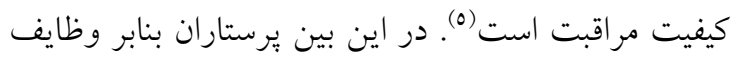
سازمانى خود نقش كمكدهنده به بيماران با شرايط حاد مر اجعهلكننده دارند و شايستخى ارتباطى براى ايجاد رابطه درمانى با بيمار ضرورى است (7).

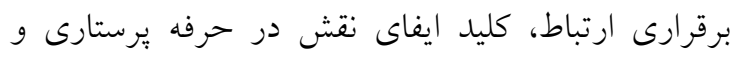

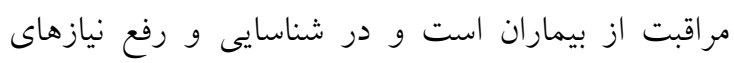

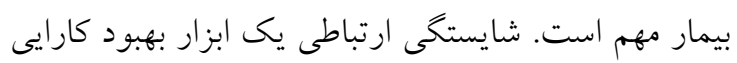

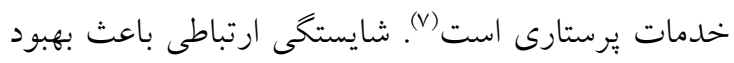

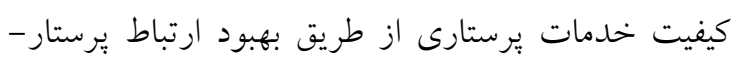

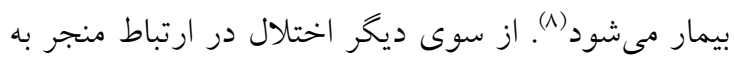

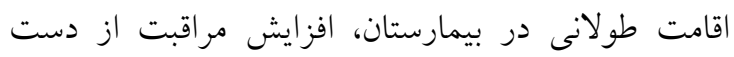

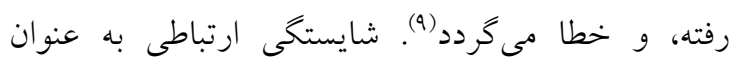

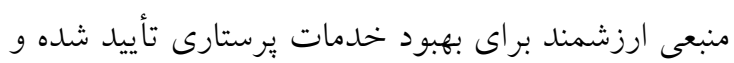

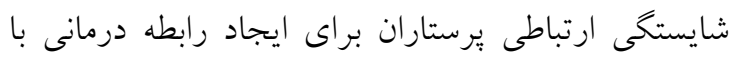

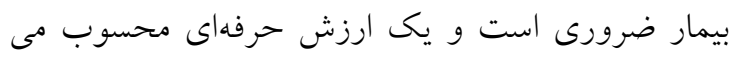

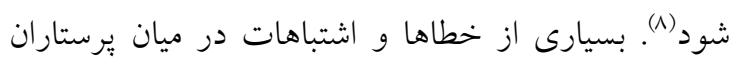
به دليل مشكل ارتباطى روى مىدهد و اين موضوع

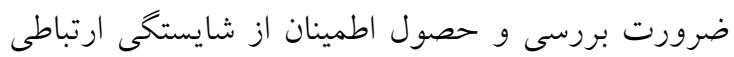

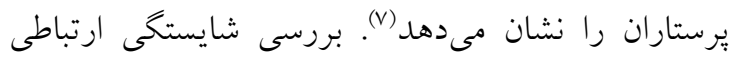

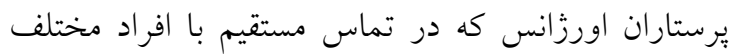
هستند اهميت دارد و ارتقاى آن به عنوان مداخله 


\begin{tabular}{|c|c|c|}
\hline درصد & تعداد & مراكز آموزشى درمانى \\
\hline $\mid V / I$ & $\varepsilon \cdot$ & فيروزكر \\
\hline IV/0 & $\varepsilon$ & حضرت رسول \\
\hline $\mid r / \varepsilon$ & rq & فيروزابادى \\
\hline$\| r / V$ & rt & هفت تير \\
\hline $7 / \varepsilon$ & 10 & ايران \\
\hline$\wedge / 1$ & 19 & شفا يحياييان \\
\hline $7 / \Lambda$ & 17 & هاشمى نزاد \\
\hline$V / N$ & 11 & على اصغر \\
\hline $0 / 1$ & ir & حضرت فاطمه \\
\hline $0 / 1$ & ir & مطهرى \\
\hline $1 \cdots$ & $r \mu \varepsilon$ & جمع كل \\
\hline
\end{tabular}

نحوه گردآورى داده در اين مطالعه خودگز ارشدهى و بـا

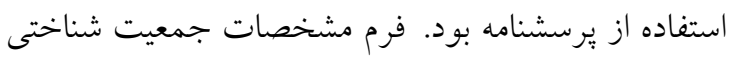
شامل برسشهايى از جمله سن، جنسيت، وضعيت تأهل،

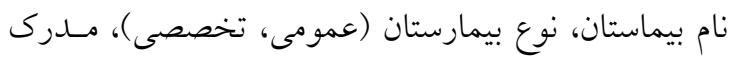

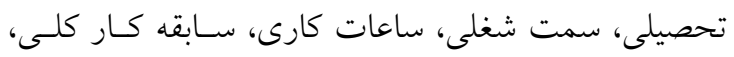

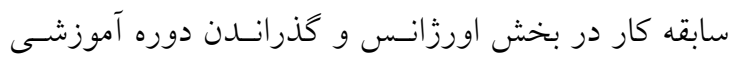

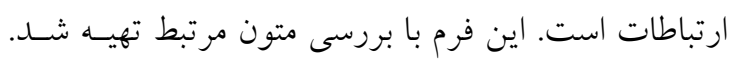

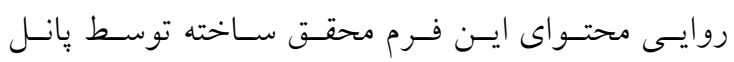

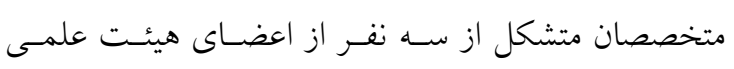

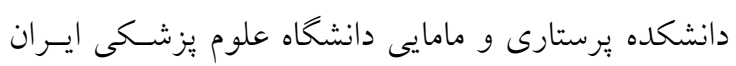
بررسى شد.

از مقيــاس شايسـتخى ارتبـاطى ( Communicative هr Competence Scale (CCS ارزيابى شايستكى ارتباطى در مقياس ليكرت ينج قسمتى دانى

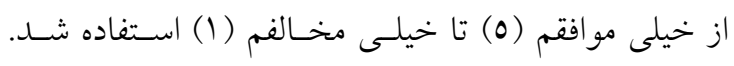

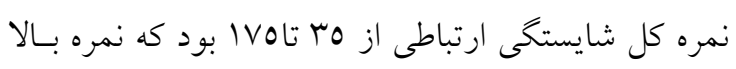

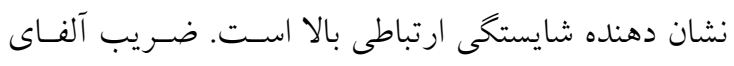

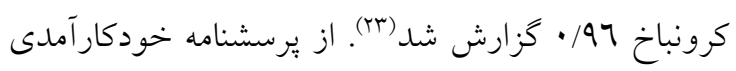
ارتبــاطى (SEQ) Self-efficacy questionnaire براى ارزيابى خودكار آمدى ارتباطى استفاده شد. اين ابـزار

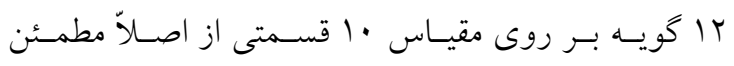

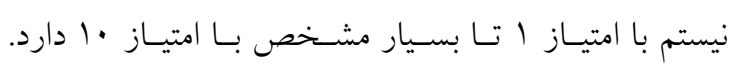

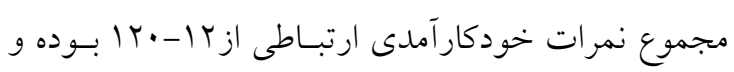

بيمار مىتواند تحت تأثير عواملى ماند متغيرهاى

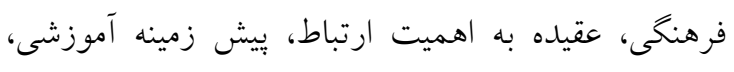

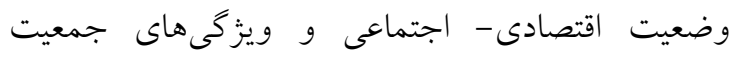

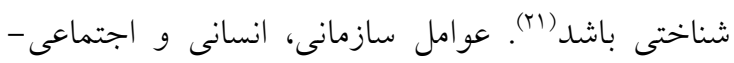

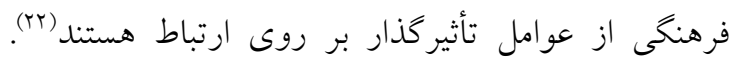

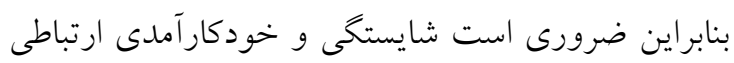

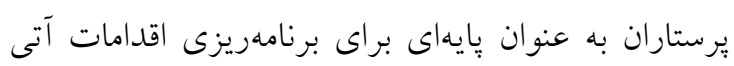

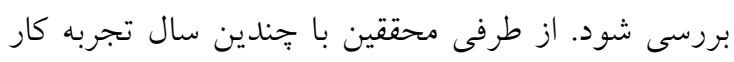

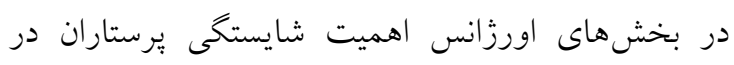

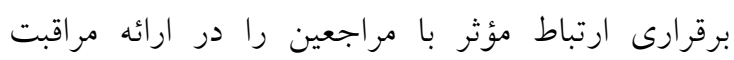

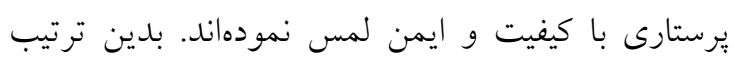

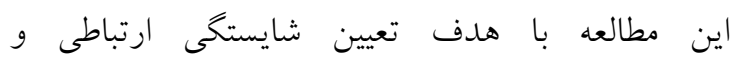
خودكار آمدى ارتباطى برستاران اورزانس انجام شد.

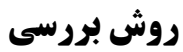

اين بُزوهش يك مطالعه مقطعى از نورع توصيفى بود كه در بخشهاى اورزانس مراكز آموزشى - درمانى دانشگاه

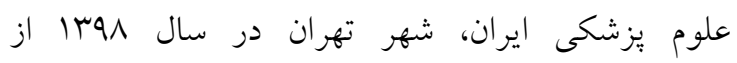

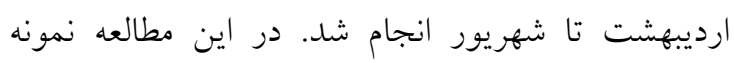
يُزوهش يرستاران اورزانس با حداقل شش ماه سابقه كار

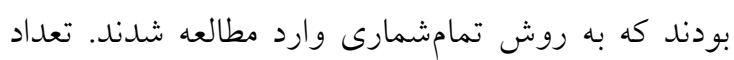

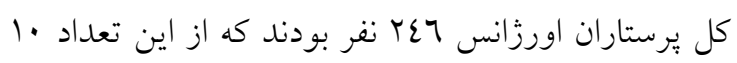

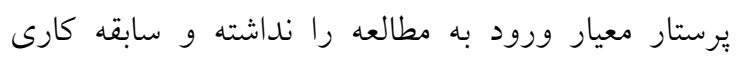
كمتر از شش ماه در بخش اورزانس داشتند و دو نفر از

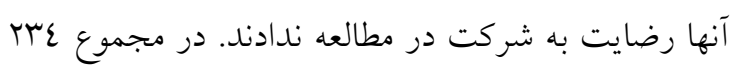
يرستار وارد مطالعه شد (جدول شماره ()).

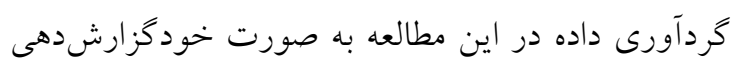

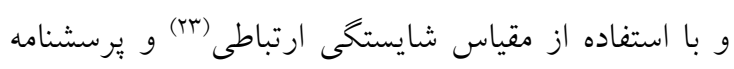

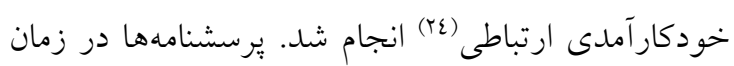
استراحت يرستاران يا ابتداى نوبت كارى توزيع شد تاري فرصت تكميل آنها را داشته باشند.

جدول شماره ا: تعداد برستاران اورزانس شركت كننده در

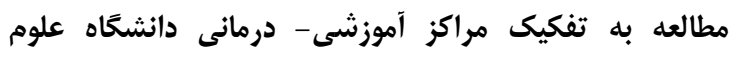
يزشى ايران 
داد. براى تسهيل بِاسخ دادن به يرسشنامهها آنهـا در زمـان

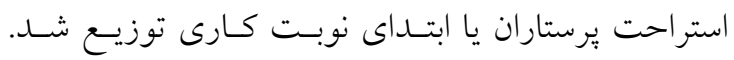

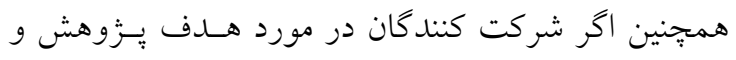

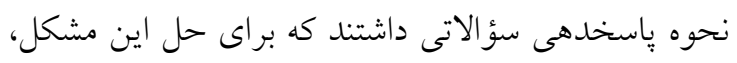

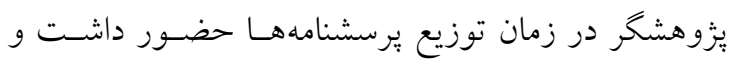

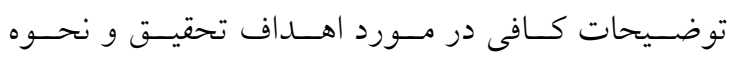

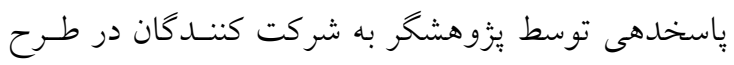

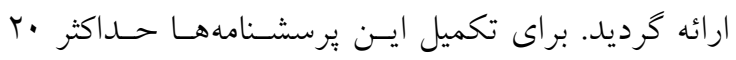

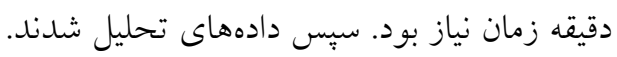
براى تحليل دادهها از آزمونهاى آمارى تى مستقل، آناليز

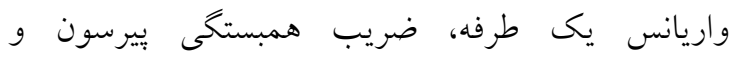

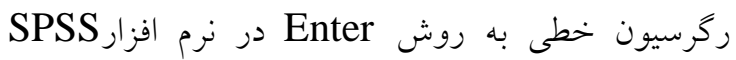

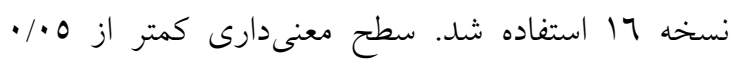

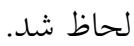

\section{يافتهها}

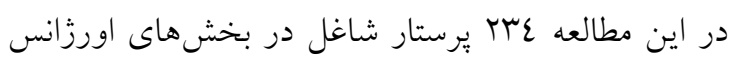

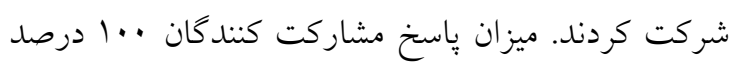

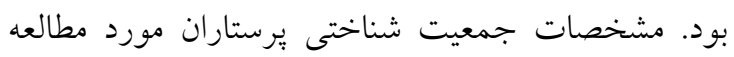
در جدول شماره r خلاصه شده است. ميانخين و انحراف

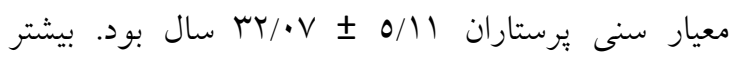
يرستاران در مطالعه را زنان (VT/0 درصد) و افراد متأهل

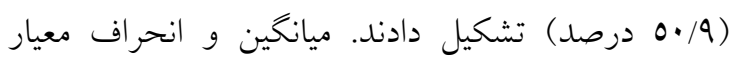

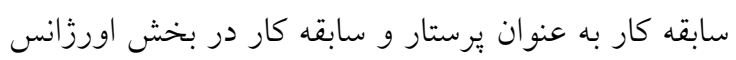

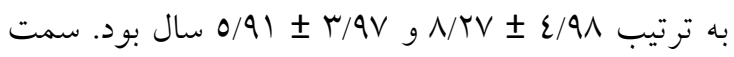

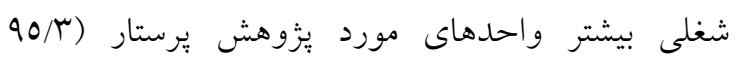

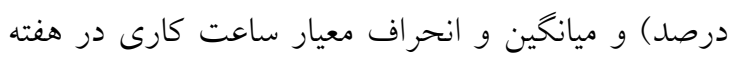

$$
\text { . }
$$

جدول شماره ז: توصيف مشخصات جمعيت شناختى برستاران

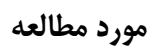

مقادير بالا نشاندهنده خودكار آمدى ارتباطى بيشتر اسـت.

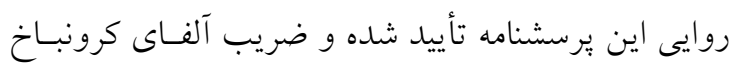

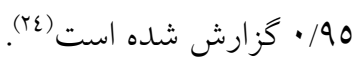
اين ابزارهاى جمع آورى داده به روش ترجمه - بازترجمه آند

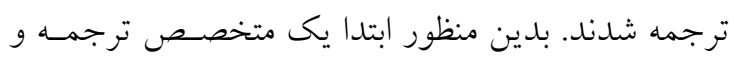

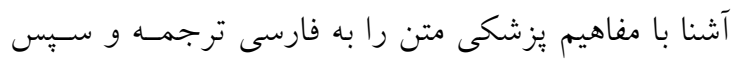

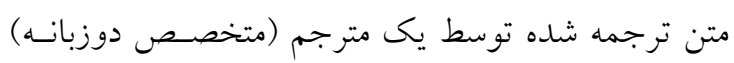

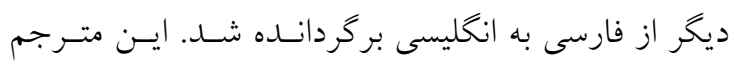

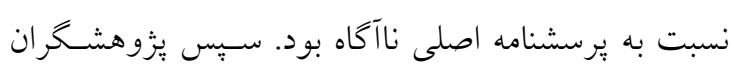

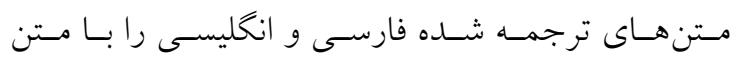
يرسشنامه اصلى مقايسه كرده و در مورد مفاهيم و وازههـا به جمع بندى رسيدند. در بررسى كيفى روايى محتـوا از

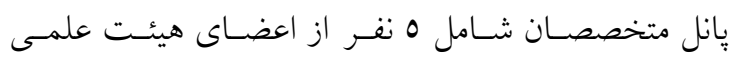

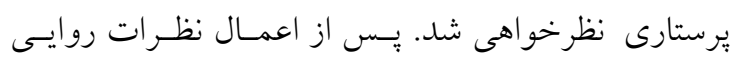

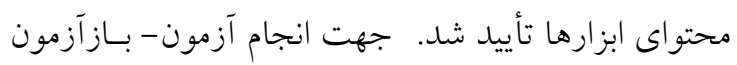
يرسشنامهها در دو مرحله به فاصله زمانى تقريباً دو هفتـهـ

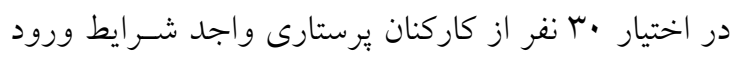

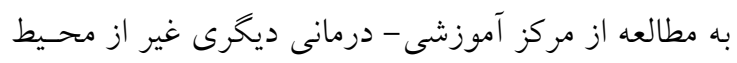

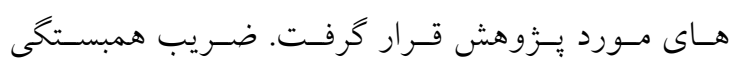

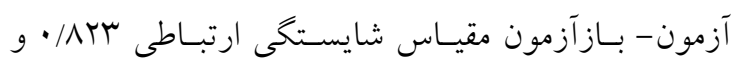

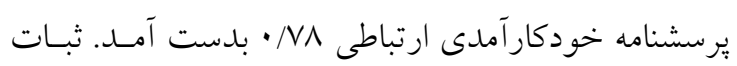
درونى مقياس شايستكى ارتباطى با ضريب آلفاى كرونباخ

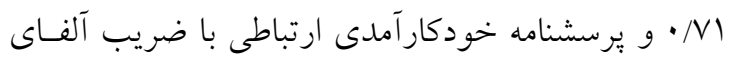
كرونباخ AV/ • تأييد شد. يُزوهشكر يس از تصويب برويوزال و دريافت كد اخـلاق (IR.IUMS.REC1398.361) دانشخاه علوم بزشكى ايران و ارائه آن به مسـؤولين مراكـز

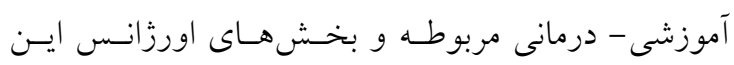

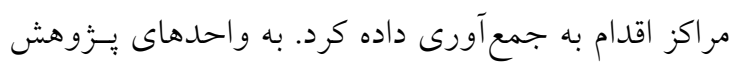

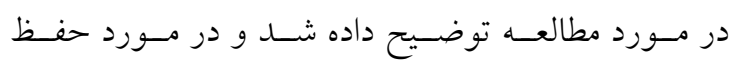

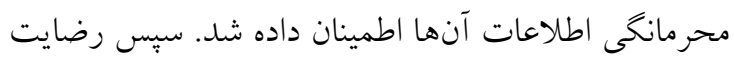

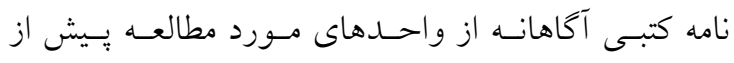

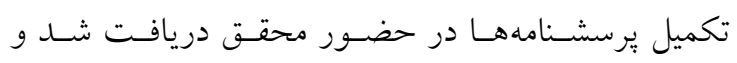

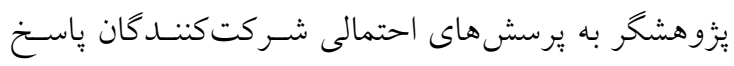


ميانخين و انحر اف معيار نمره شايستخى ارتباطى 9 × 10/

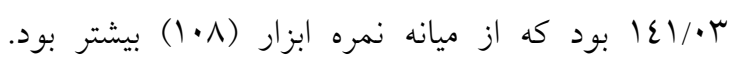
بيشترين ميانخين و انحراف معيار شايستخى ارتباطى مربوط به كويههاى "به ديخران اجازه مىدهيد كه بدانند

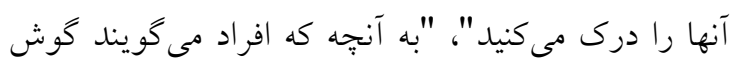

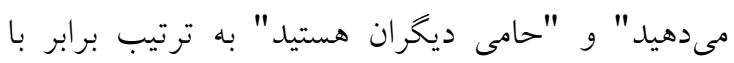
• ميانخين مربوط به گويه "به ملاقات و مكالمه با غريبهها

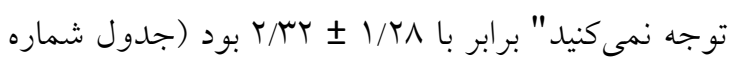
() ميانخين و انحراف معيار نمره خودكارآمدى ارتباطى

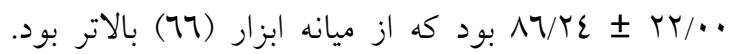

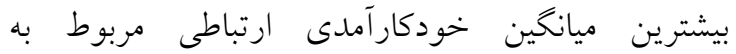
"رفتارهاى غير كلامى مناسب (مانند تماس جششمى، حالت جهره، ايما و اشاره) در طول كفتخو داشته باشيد؟" بود

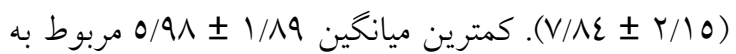
"براى كفتخو با بيمار برنامهاى از بيش آماده شده تهيه

$$
\text { كنيد." بود (جدول شماره ع). }
$$

\begin{tabular}{|c|c|c|}
\hline آمارههاى توصيفى & \multicolumn{2}{|c|}{ مشخصات جمعيت شناختى } \\
\hline $\begin{array}{c}r Y / \cdot V(0 / 11) \\
(Y r-01)^{€}\end{array}$ & \multicolumn{2}{|c|}{ 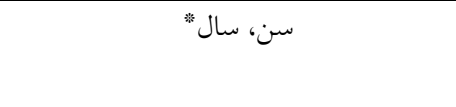 } \\
\hline $00(T / / 0)$ & مرد & جنسيت :"* \\
\hline IVq (V7/O) & زن ان & \\
\hline$\| r(\varepsilon \wedge / r)$ & مجرد & وضعيت \\
\hline $\operatorname{lrT}(01 / \mathrm{N})$ & 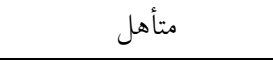 & تأهل \\
\hline $1 \mu \wedge(09 / \cdot)$ & 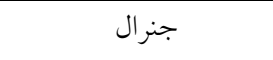 & نوع بيمارستان \\
\hline $97(\Sigma) / \cdot)$ & تخصصى & *** \\
\hline $199(10 / \cdot)$ & كارشناسى & آخرين مدرى \\
\hline ro $(10 / \cdot)$ & كارشناسى ارشد وبالاتر & تحصيلى"**" \\
\hline $\begin{array}{c}\Lambda / T V(\Sigma / q \Lambda) \\
(\text { (ol } 1 \cdot--J V)^{€}\end{array}$ & \multicolumn{2}{|c|}{ سابقه كار، سال" } \\
\hline 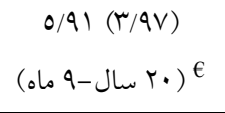 & \multicolumn{2}{|c|}{ سابقه كار در بخش اورزانس، سال" } \\
\hline$r T r(90 / \Gamma)$ & يرستار & سمت شغلى" "* \\
\hline $11(\varepsilon / v)$ & سريرستار & \\
\hline 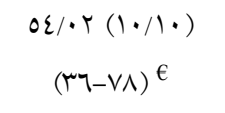 & \multicolumn{2}{|c|}{ ساعت كارى در هفته، ساعت" } \\
\hline $10 \mathrm{~V}(\mathrm{TV} / \mathrm{I})$ & بله & كذران دوره \\
\hline$V V(Y T / Q)$ & خير & آموزشى \\
\hline 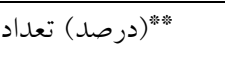 & (بيشينه، كم & "انتحر اف معيار \\
\hline
\end{tabular}

جدول شماره ऍّ: توزيع فراوانى شايستكى ارتباطى ثرستاران مورد مطالعه به تفكيك تويهها

$r / q 1 \pm \cdot / 71$
$r / q V \pm \cdot / 7 V$
$\varepsilon / \cdot \varepsilon \pm \cdot / 7 V$
$r / \wedge \varepsilon \pm \cdot / q V$
$r / V \varepsilon \pm 1 / / 0$
$\varepsilon / \cdot \cdot \pm \cdot / 7 q$
$\varepsilon / 1 \cdot \pm \cdot / 7 /$
$\varepsilon / \cdot r \pm \cdot / q q$
$\varepsilon / \cdot \cdot \pm \cdot / V \varepsilon$
$r / 0 r \pm \cdot / \wedge \varepsilon$
$\varepsilon / \cdot 7 \pm \cdot / q V$
$\varepsilon / \cdot 0 \pm \cdot / q V$
$\varepsilon / \cdot 0 \pm \cdot / 7 r$
$\varepsilon / / 0 \pm \cdot / V \cdot$
$\varepsilon / / r \pm \cdot / 07$
$\varepsilon / \cdot r \pm \cdot / V \cdot$

ارتباط برقرار كردن با ديخران را آسان مى يابيد.

مى توانيد با موقعيتهاى مختلف سازكار شويد.

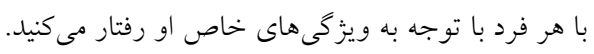
در طول صحبت حرف سايرين را بسيار قطع مى كنيد. در قبال صحبت كردن با سايرين به دنبال منفعت هستيد. مىتوانيد بطور مؤثر با ديخران ارتباط برقرار كنيد.

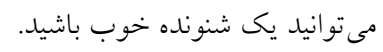
رابطه شخصى سرد و خشكى داريد. صحبت كردن با سايرين برايتان آسان است. فقط براى اثبات حقانيت خود با ديخران بحث نمى كنيد. در طول مكالمه رفتار ملايمى نداريد. احساسات افراد را ناديده مى كيريد. بطور كلى احساسات ديخران را درك مى كنيد. به ديخران اجازه مىدهيد كه بدانند آنها را درك مى كنيد. سايرين را درك مى كنيد. $\wedge \wedge$ در هنخام صحبت كردن آسوده و راحت هستيد. 


\begin{tabular}{|c|c|}
\hline$\varepsilon / 10 \pm \cdot / 0 \mathrm{~V}$ & به آنجه كه افراد مى گويند كوش مىدهيد. \\
\hline$\varepsilon / \cdot \varepsilon \pm \cdot / V \cdot$ & مايليد با افراد صميمى و راحت باشيد. \\
\hline$\varepsilon / \cdots \pm \cdot / 7\rceil$ & به طوركلى مى دانيد جه رفتارى متناسب با پهه موقعيتى است. \\
\hline$r / q \varepsilon \pm \cdot / V q$ & در خواست غير معمول از دوستانتان نمى كنيد. \\
\hline$r / \Lambda \varepsilon \pm \cdot / \Lambda 1$ & يك سخنران تأثير كذار هستيد. \\
\hline$\varepsilon / 10 \pm \cdot / 11$ & حامى ديخران هستيد. \\
\hline$T / \mu r \pm 1 / Y \Lambda$ & به ملاقات و مكالمه با غريبهها توجه نمى كنيد. \\
\hline$r / \Lambda \Lambda \pm \cdot / \mu$ & به آسانى خودتان را جاى ديخران قرار مىدهيد. \\
\hline$\varepsilon / \cdot \wedge \pm \cdot /\urcorner)$ & به كفتخو توجه داريد. \\
\hline$r / \Lambda V \pm \cdot / V V$ & به طور كلى در هنگحام كفتخو با افراد جديد احساس راحتى مى كنيد. \\
\hline$r / 91 \pm 1 / \cdot v$ & به آنجه ديخر ان در هنخام گفتخُو مى گو يند علاقه نشان مىدهيد. \\
\hline$r / 9 r \pm \cdot / 77$ & خيلى خوب كفتكو را دنبال نمى كنيد. \\
\hline$r / 10 \pm \cdot / N r$ & از كردهمايىهاى اجتماعى كه مىتوانيد در آنجا افراد جديد را ملاقات كنيد لذت مىبريد. \\
\hline$\varepsilon / 1 \cdot \pm \cdot /\rceil$ & يك فرد دوست داشتنى هستيد. \\
\hline$r / 91 \pm \cdot / 7 \Lambda$ & يك فرد انعطاف يذير هستيد. \\
\hline$r / 01 \pm 1 / r \mu$ & از كفتحو با افراد بالا دست هراسى نداريد. \\
\hline$\varepsilon / \cdot\urcorner \pm \cdot / v \cdot$ & افراد براى حل مشكلاتشان مىتو انند به شما مراجعه كنند. \\
\hline$\varepsilon / \cdot\urcorner \pm \cdot / v \cdot$ & به طور كلى مسائل درست را در زمان صحيح مطرح مى كنيد. \\
\hline$\varepsilon / \cdot 9 \pm \cdot / V \cdot$ & دوست داريد از صدا و حركات گوياى بدن استفاده كنيد. \\
\hline$\varepsilon / \cdot \wedge \pm \cdot / 7\rceil$ & در هر لحظه به برآوردن نيازهاى ديخران حساس هستيد. \\
\hline $\mid \varepsilon 1 / \cdot r \pm 10 / \cdot 9$ & 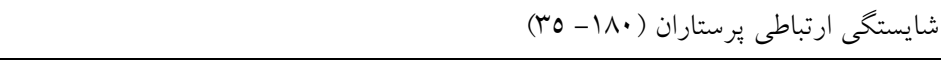 \\
\hline
\end{tabular}

جدول شماره ع: توزيع فراوانى خودكار آمدى ارتباطى يرستاران مورد مطالعه به تفكيك تويهها

\begin{tabular}{|c|c|}
\hline انحراف معيار \ ميانخين & جقدر مطمئن هستيد كه در موارد زير موفق و توانمند مىباشيد؟ \\
\hline$T / \varepsilon r \pm 1 / A r$ & موضوعاتى را كه بيمار تمايل به ابراز آن در طول كفتكو دارد را شناسايى كنيد. \\
\hline $0 / 91 \pm 1 / 19$ & براى كفتخو با بيمار برنامهاى از ييش آماده شده تهيه كنيد. \\
\hline$V / \cdots \pm r / l \cdot$ & بيمار را براى شرح مشكلات و نخر انىهايش برانخيزانيد. \\
\hline$V / r V \pm r / T_{0}$ & بدون قطع كردن كلام يا بر هم زدن تمركز با دقت و توجه كوش دهيد. \\
\hline$V / O r \pm r / / r$ & بيمار را براى بيان افكار و احساساتش تشويق كنيد. \\
\hline$V / T \Lambda \pm Y / l$ & كفتخو با بيمار را سازماندهى كنيد. \\
\hline$V / \Lambda \varepsilon \pm Y / 10$ & رفتارهاى غير كلامى مناسب مانند (تماس جشمى، حالت جهره، ايما و اشاره) در طول كفتخو داشته باشيد. \\
\hline$V / 77 \pm r / l$. & همدلى با بيمار (توجه به نظرات و احساسات) را نشان دهيد. \\
\hline$V / T Y \pm T / \cdot r$ & آنجه كه بيمار مى داند را شفاف سازى كنيد تا به مقدار صحيح اطلاعات را با او به اشتراى بخذاريد. \\
\hline$V / r T \pm r / \cdot 1$ & آكَاهى بيمار از اطلاعات داده شده را بررسى كنيد. \\
\hline$V / \cdot 7 \pm 1 / 9 \Lambda$ & برنامهاى بر اساس تصميمات مشترك بين خود و بيمار ايجاد كنيد. \\
\hline$V / \nearrow \cdot \pm r / r \cdot$ & كَفتكو را بِ از اطمينان از اينكه به سؤالات بيمار بِاسخ داده شده است خاتمه دهيد. \\
\hline$\Lambda T / r \varepsilon \pm T r / \cdots$ & 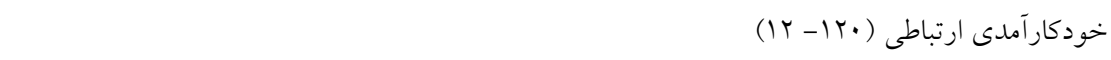 \\
\hline
\end{tabular}

تحصيلى ( P=•/1) از نظر شايستكى ارتباطى تفاوت

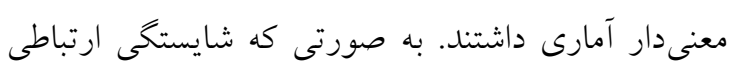

نتايج آزمون تى تست نشان داد يرستاران در گروههاى

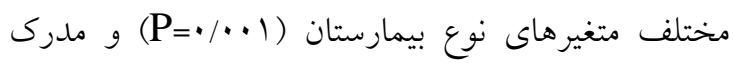


متغيرهاى جمعيت شناختى و خودكارآمدى ارتباطى تفاوت معنى دار آمارى مشاهده نشد (جدول شماره 0).
يرستاران شاغل در بيمارستان تخصصى از جنرال و يرستاران داراى مدرى تحصيلى كارشناسى ارشد از افراد

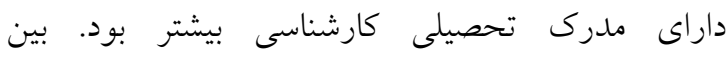

جدول شماره 0: ارتباط مشخصات جمعيت شناختى كيفى با شايستكى ارتباطى و خودكار آمدى ارتباطى برستار ان مورد مطالعه

\begin{tabular}{|c|c|c|c|c|c|c|}
\hline \multicolumn{2}{|c|}{ خودكارآمدى ارتباطى } & \multicolumn{2}{|c|}{ شايستخى ارتباطى } & \multirow[t]{2}{*}{ تعداد } & \multirow{2}{*}{\multicolumn{2}{|c|}{ مشخصات جمعيت شناختى }} \\
\hline نتايج آزمون تى تست & انحراف معيار \ ميانكين & نتايج آزمونتى تست & انحراف معيار 士ميانخين & & & \\
\hline $\mathrm{t}=\cdot / \mathrm{TV} \quad \mathrm{df}=r r \Lambda$ & $\Lambda V / Q \Lambda \pm r \cdot / \Lambda r$ & $t=-\cdot / \pi r$ & $1 \varepsilon \cdot / 0 \Lambda \pm 17 / 0 \mathrm{~V}$ & 00 & مرد & جنسيت \\
\hline $\mathrm{P}=\cdot / 0$ & $\Lambda 0 / \pi \pm \Psi r / r \Lambda$ & $\mathrm{df}=r \mu r \quad \mathrm{P}=\cdot / \Lambda \mid$ & $1 E 1 / 17 \pm 10 / N Y$ & iva & 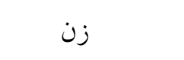 & \\
\hline $\mathrm{t}=-\cdot / \tau \varepsilon$ & $10 / r 7 \pm r r / T r$ & $\mathrm{t}=\cdot \pi r$ & $|\varepsilon| / \varepsilon \pm \mid \varepsilon / \varepsilon \wedge$ & $11 r$ & مجرد & وضعيت \\
\hline $\mathrm{df}=r r_{0} \quad \mathrm{P}=\cdot / 01$ & $\Lambda V / r O \pm r Y / 90$ & $\mathrm{df}=r r q \quad \mathrm{P}=\cdot / q \wedge$ & $|\varepsilon \cdot / 99 \pm| \varepsilon / \cdot \varepsilon$ & irr & متأهل & تأهل \\
\hline $\mathrm{t}=-\cdot / 70$ & $10 / 2 r \pm r / / 10$ & $\mathrm{t}=-r / r r$ & $|r N / r| \pm \mid 7 / \cdot \Lambda$ & ir & جنرال ل & 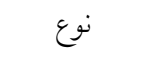 \\
\hline $\mathrm{df}=r Y \wedge \quad P=\cdot / 01$ & $\Lambda V / r 7 \pm r r / 19$ & $\mathrm{df}=r \mu r \quad P=\cdot / \cdot \cdot$ & $|\varepsilon 0 / \cdot \Lambda \pm| \varepsilon / v \wedge$ & 97 & تخصصى & بيمارستان \\
\hline $\mathrm{t}=-1 / T 1$ & $10 / 29 \pm r Y / 17$ & $t=-r / 27$ & $179 / 97 \pm 10 / 27$ & 199 & كارشناسى & آخرين مدرى \\
\hline $\mathrm{df}=r Y \wedge \quad P=\cdot / r r$ & $q \cdot / \varepsilon \cdot \pm r \cdot / \Lambda \varepsilon$ & $\mathrm{df}=\operatorname{rrr} \quad \mathrm{P}=\cdot / \cdot 1$ & $|\varepsilon V / \cdot v \pm| V / \mid \Lambda$ & ro & كارشناسى ارشدو & تحصيلى \\
\hline $\mathrm{t}=-1 / \mathrm{TV}$ & 10/va $\pm r / / v_{0}$ & $\mathrm{t}=\cdot / \mathrm{IV}$ & $|\varepsilon| / \cdot \vee \pm \mid \gamma /$ & Trr & ل ميرستار & سمت شغلى \\
\hline $\mathrm{df}=r \mu \wedge \quad P=\cdot / / V$ & $q \cdot / r \Psi \pm r q / \cdot$ & $\mathrm{df}=r \mu \mathrm{Tr} P=\cdot / \Lambda \uparrow$ & $1 \varepsilon \cdot \pi \cdot \pm 1 \varepsilon / \pi \varepsilon$ & 11 & سريرستار & \\
\hline $\mathrm{t}=\cdot / \Lambda \mathrm{r} \quad \mathrm{df}=r \mathrm{r} \Lambda$ & $\wedge V / \cdot V \pm Y r / T l$ & $\mathrm{t}=1 / 01$ & $1 \varepsilon r / 1 r \pm 10 / 0 r$ & lov & بله & كَذران دوره \\
\hline $\mathrm{P}=\cdot / \varepsilon 1$ & $\Lambda F / \Delta F \pm r \cdot / V r$ & $\mathrm{df}=r \mu \mathrm{P}=\cdot / \mu$ & $|r \Lambda N \wedge \pm 17 / 0|$ & w & خير & آموزشى \\
\hline
\end{tabular}

نتايج آزمون همبستخى بيرسون نشان داد بين متغير ساعت

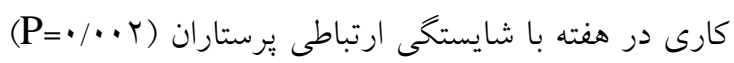

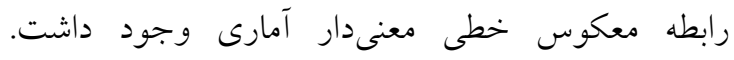

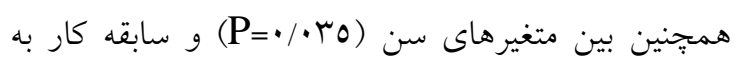

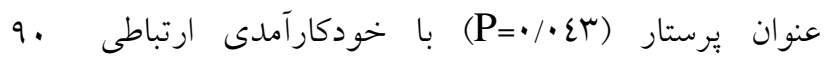
يرستاران رابطه مستقيم خطى و با ساعت كارى در هفته

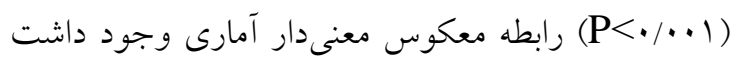

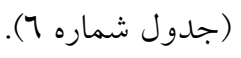

جدول شماره 7: ارتباط مشخصات جمعيت شناختى كمى با باريا

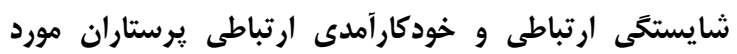


متغيرهاى ساعت كارى در هفته، نوع بيمارستان و سطح تحصيلات تبيين شده است (جدول شماره V).
بر شايستكى ارتباطى يرستاران داشت. ضريب تعيين در

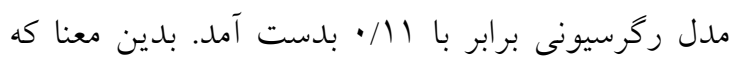

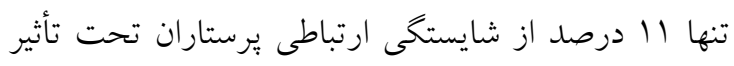

جدول شماره V: ركَرسيون خطى جهت بررسى تؤثير عوامل جمعيت شناختى با شايستكى ارتباطى يرستاران مورد مطالعه

\begin{tabular}{|c|c|c|c|c|c|c|c|c|}
\hline \multirow[t]{2}{*}{$R^{2}$} & \multicolumn{2}{|c|}{ فاصله اطمينان } & \multirow[t]{2}{*}{ p-value } & \multirow{2}{*}{ آزآمون } & \multirow{2}{*}{ ضرانب استدارد } & \multirow{2}{*}{ ضرلب } & \multirow{2}{*}{\multicolumn{2}{|c|}{ متغير هاى مستقل }} \\
\hline & حد بالا & حد بايين & & & & & & \\
\hline \multirow[t]{6}{*}{.$/ 11$} & $19 \cdot / r \Lambda$ & $10 N / 2 \pi$ & $<\cdot / \cdot \cdot 1$ & YI/OV & - & $\mid V \varepsilon / \mu T$ & لمدار ثابت & \\
\hline & $-\cdot / 1 V$ & $-\cdot / T T$ &.$\cdots 1$ & $-r / \varepsilon V$ & $-\cdot / \pi \varepsilon q$ & $-\cdot / \pi q$ & كارى در هفته & \\
\hline & & & مرجع & & & & تخصصى & نوع بيمارستان \\
\hline & $-r / N 1$ & $-11 / 9 r$ & $<\cdot / \cdot \cdot 1$ & $-r / \Lambda 1$ & $-\cdot / r \varepsilon \varepsilon$ & $-V / A V$ & جنرال ل & \\
\hline & & & مرجع & & & & كارشناسى ارشد و بالاتر & سطح \\
\hline & $-\cdot / M$ & $-11 / \lambda r$ & . $/ 4 \pi$ & $-Y / Y \Lambda$ & $-\cdot / r \varepsilon$ & $-7 / \pi 7$ & كارشناسى & تحصيلات \\
\hline
\end{tabular}

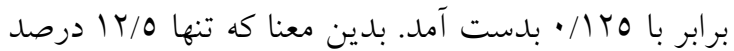

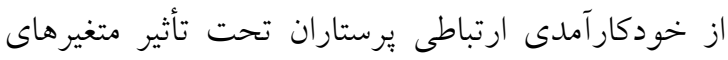
جمعيت شناختى تبيين شده است (جدول شماره ^).
نتيجه رگرسيون جند كانه خطى به روش همزمان نشان داد

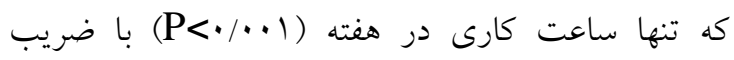
استاندارد ارتباطى معنىدار شد. ضريب تعيين در مدل ركرسيونى

جدول شماره A: ركر سيون خطى جهت بررسى تأثير عوامل جمعيت شناختى با خودكارآمدى ارتباطى يرستاران مورد مطالعه

\begin{tabular}{|c|c|c|c|c|c|c|c|}
\hline \multirow[t]{2}{*}{$R^{2}$} & \multicolumn{2}{|c|}{ فاصله اطمينان } & \multirow[t]{2}{*}{ p-value } & \multirow{2}{*}{ آَآمون } & \multirow{2}{*}{ استاندارد } & \multirow{2}{*}{ ضريب } & \multirow[t]{2}{*}{ متغيرهاى مستقل } \\
\hline & حد بالا & حد بايين & & & & & \\
\hline \multirow{4}{*}{.$/ 1 T_{0}$} & 107 & $\Lambda \cdot / r \cdot \Lambda$ & $<\bullet / \cdot \bullet$ & T//६| & -- & $11 N / 1.7$ & مقدار ثابت \\
\hline & $1 / 9 \cdot r$ & $-\cdot / \Lambda \mid Y$ & $\cdot / \varepsilon r$ & ./val &.$/ 1 T 7$ & .1020 & 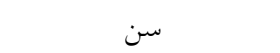 \\
\hline & . NTA & $-r / T Y T$ & . &.- .1970 & $-\cdot / 101$ & $-\cdot / 799$ & سابقه كار بهعنوان يرستار \\
\hline & $-. \cdot 10 . r$ & $-1 / 11$ & $<\cdot / \cdot \cdot 1$ & $-0 / r T a$ & $-\cdot / r V$ & $-\cdot / \Lambda \cdot v$ & ساعت كارى در هفته \\
\hline
\end{tabular}

يرستاران به واسطه نقشى كه دارند بايد ارتباطات گسترده با بيماران و ساير كاركنان سلامت داشته باشند از اين رو شايستى ارتباطى كه در مشاركت كنندكان در اين مطالعه بالا بود، اصلى مهم در ارائه مراقبتهاى يُرستارى

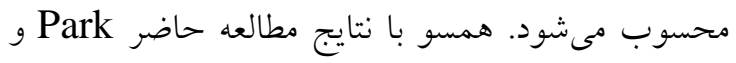

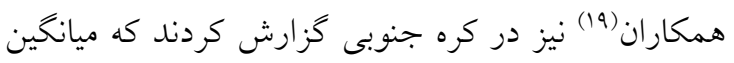

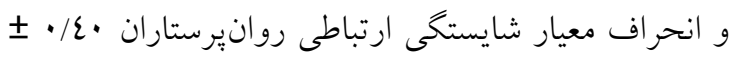

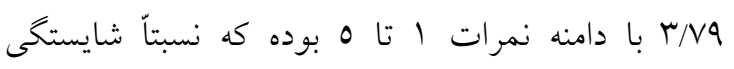

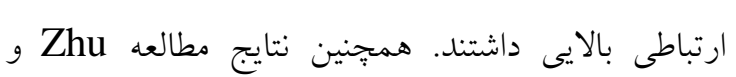

\section{بحث و نتيجدكيرى} بر اساس نتايج مطالعه حاضر شايستخى ارتباطى برستار بان شاغل در بخش اورزانس مر اكز آموزشى - درمانى دانشخاه

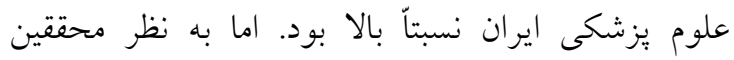
ضرورى است يرستاران در اين زمينه شايستىى حداكثرى داشته باشند تا بتوانند به نحو مطلوب و با كيفيت بالا به اله اله

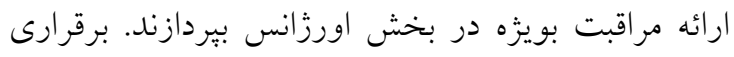

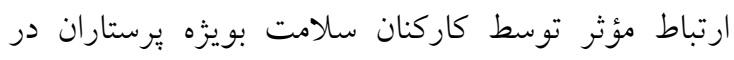
ارتقاى كيفيت مراقبت و حفظ ايمنى بيمار ضرورى است. 
بيمارستانهاى تكى تخصصى نمره بالاترى در مقايسه با

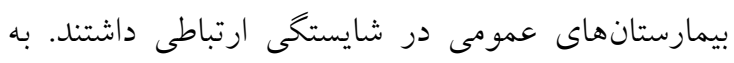

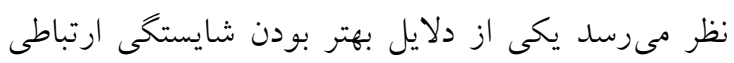
يرستاران اورزانس در بيمارستانهاى تكى تخصصى، كمتر

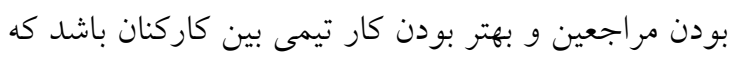

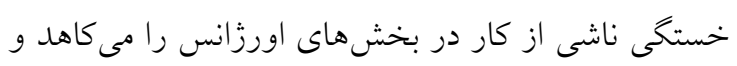

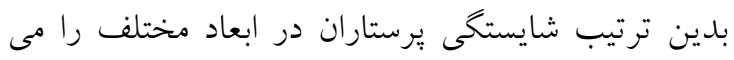

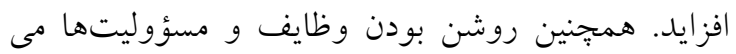

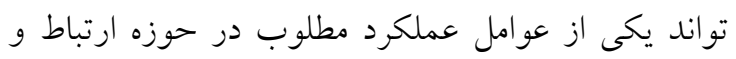

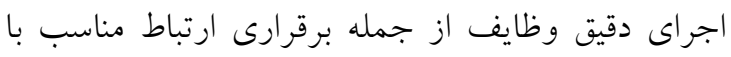

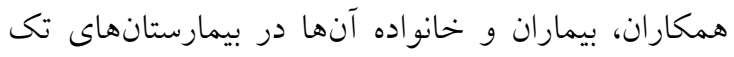
تخصصى باشد. هر جند مطالعه مشابه در تأييد نتايج اين

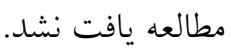

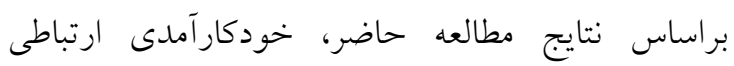
برستاران شاغل در بخش اورزانس نسبتاً بالا بود. بيشترين

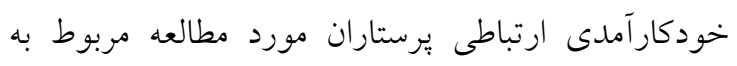

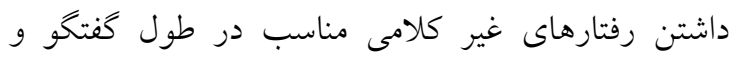

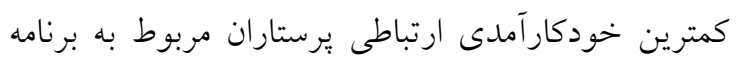

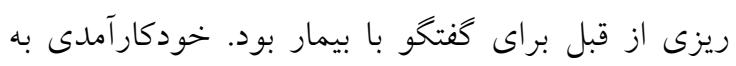

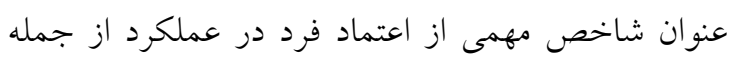

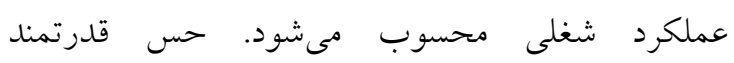

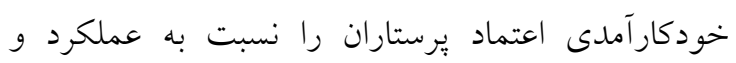

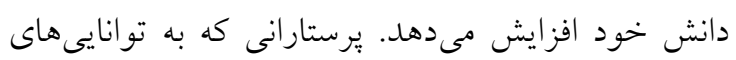
خود در تمام حوزهها از جمله برقرارى ارتباط مؤثر

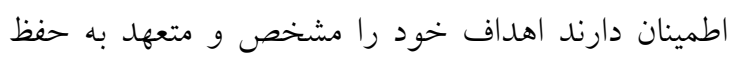

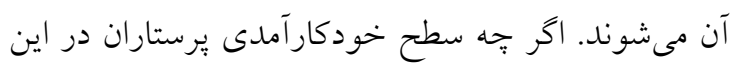

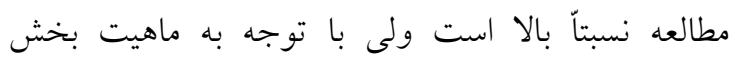

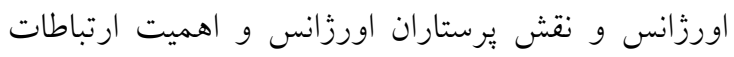

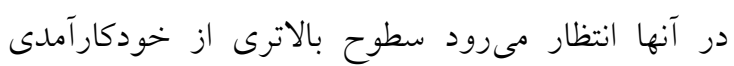
وجود داشته باشد. در مطالعهاى در دانمارى ميانكين

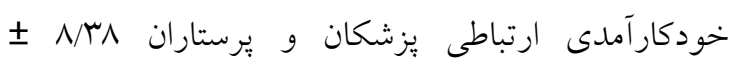

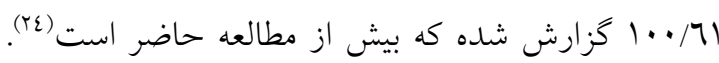

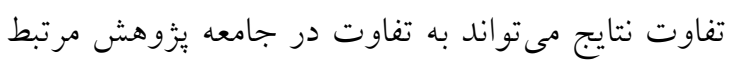
باشد. Kim نشان داد كه خودكارآمدى دانشجويان
همكاران در كشور جين نشان داد كه ميانخين و انحراف

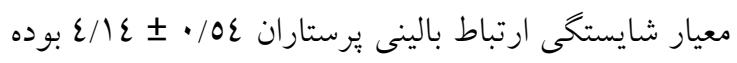

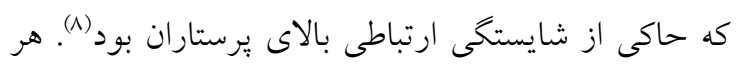

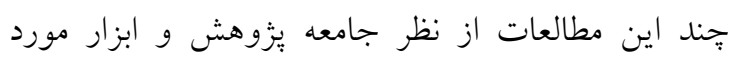

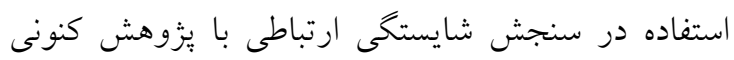
متفاوت هستند. در مطالعه ديخرى در كره جنوبى ميانگين

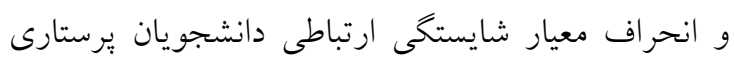

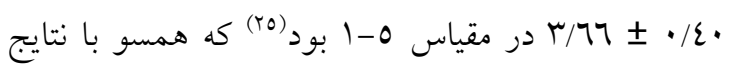
يزوهش حاضر است هر جند دو مطالعه از نظر جامعه

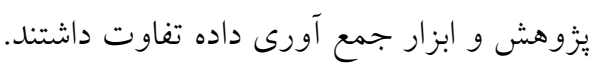

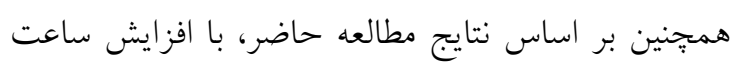

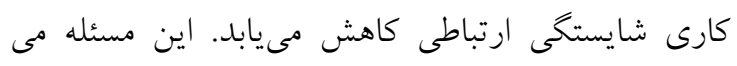

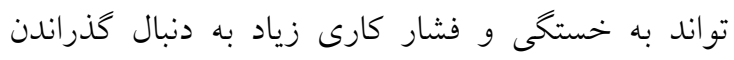

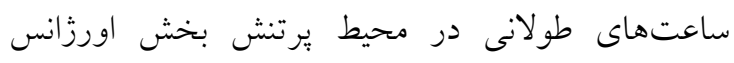

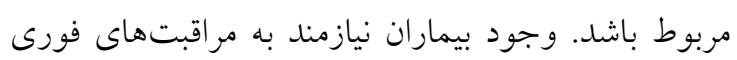

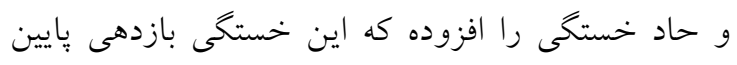

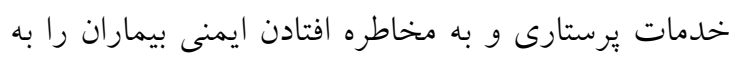

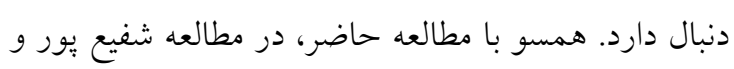
همكاران در ايران گزارش شد كه حجم زياد كار و تعداد

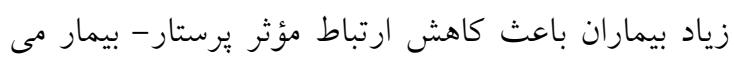
شود و خستكى فزاينده مىتواند تعاملات و عملكرد يرستاران را در تمام جنبهها تحت الشعاع قرار دهد (بحن).

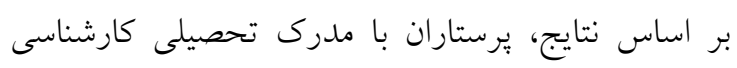

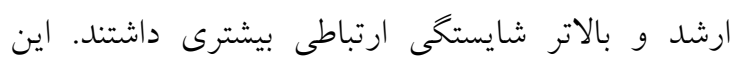

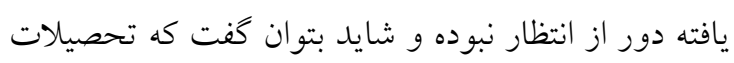

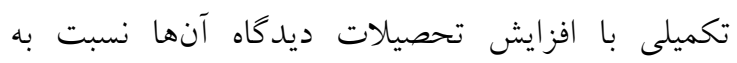

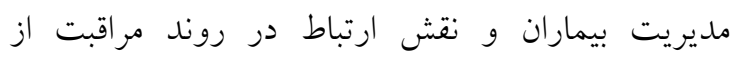

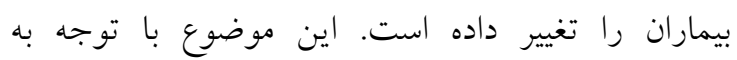

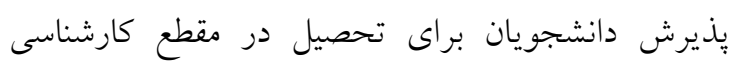
ارشد در رشته يرستارى اورزانس در ايران در خجند سال

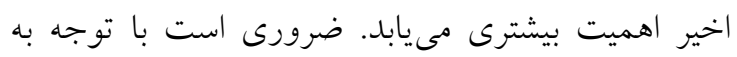

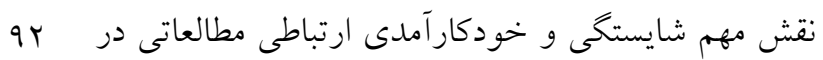

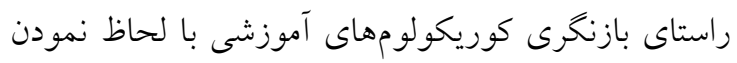

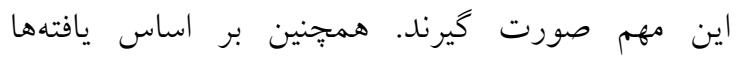




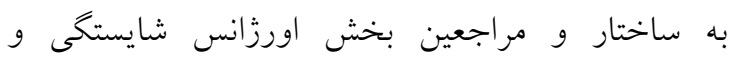

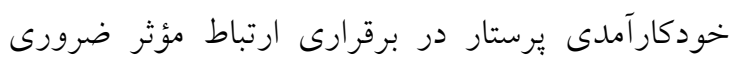

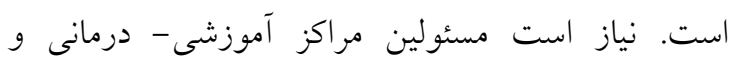

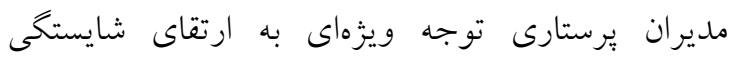

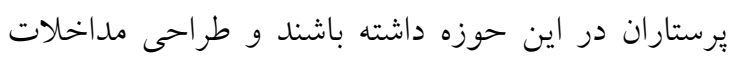

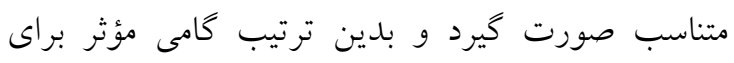

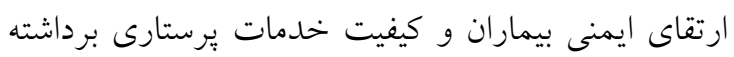

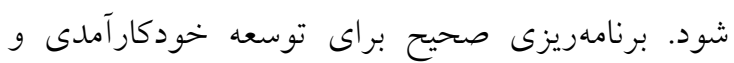

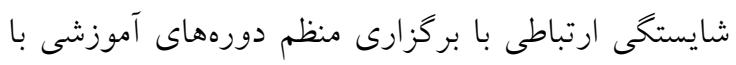

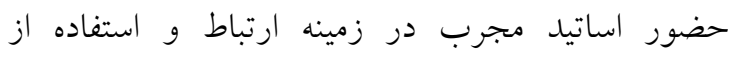
رويكردهاى آموزشى همجيون منتورى و بركزارى جلسات

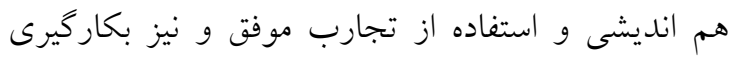

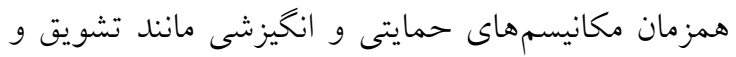

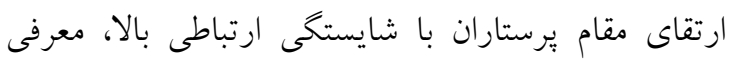

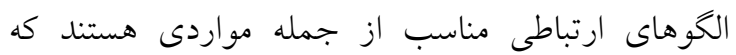

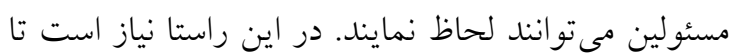

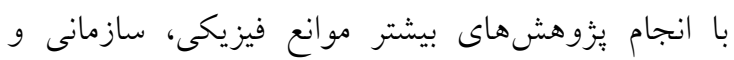

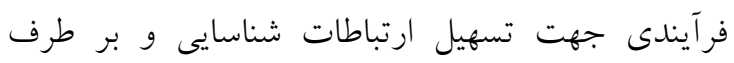

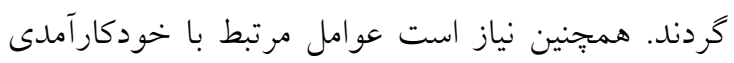

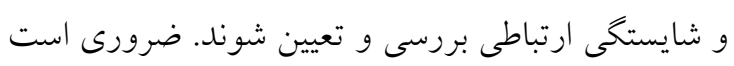

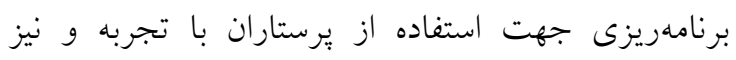
تحصيلات بالاتر و تخصصى در اورزانس صورت كيرد.

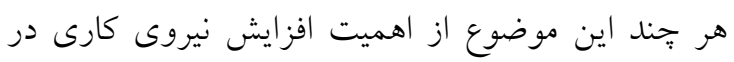
بخشهاى اورزانس و كاهش باركارى يرستاران در جهت ارتقاى كيفيت خدمات و بهبود ايمنى بيماران نمى كاهد.

تعارض منافع: هيج كونه تعارض منافعى توسط نويسندكان بيان نشده است.

\section{تقدير و تشكر}

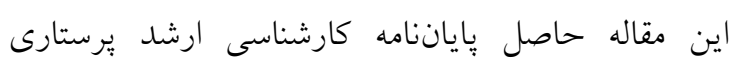

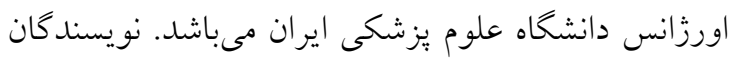

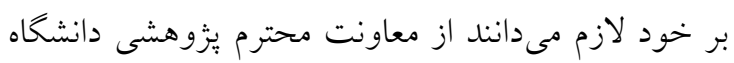

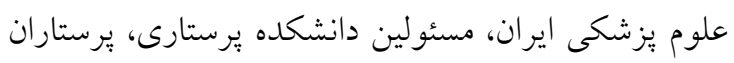

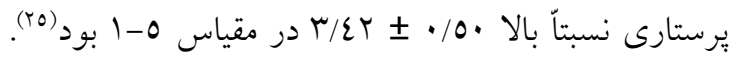

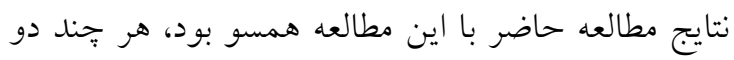
مطالعه از نظر واحدهاى مورد يُزوهش تفاوت داشئ داشتند،

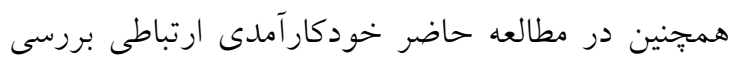
شد و در مطالعه Kim خودكارآمدى عمومى مورد بررسى قرار كرفت. هم:جنين بر اساس نتايج اين مطالعه ساعت كارى در هفته

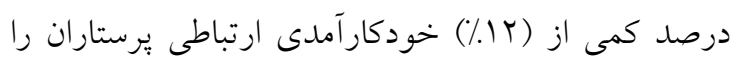

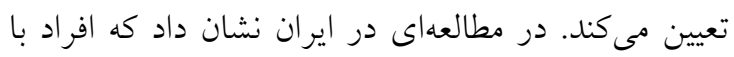
سابقه كارى بالاتر به دليل بيشتر بودن تجربه كارى و ودئل

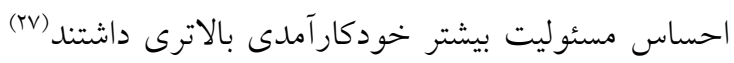

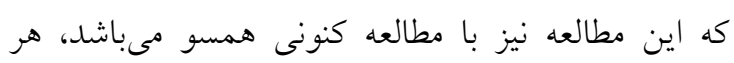

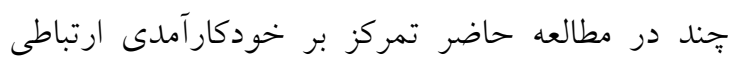

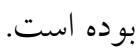
از محدوديت اين بُزوهش همكارى كم مشاركت كنندكان جهت ير كردن يرسشنامها به علت مشغله زياد كارى

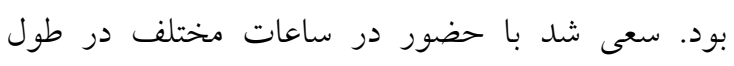

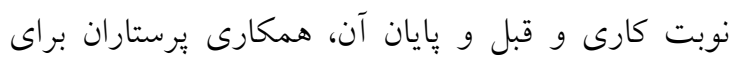

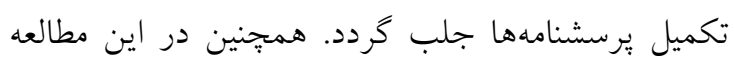

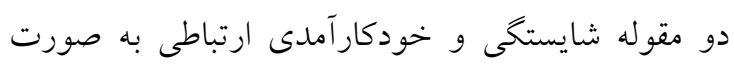

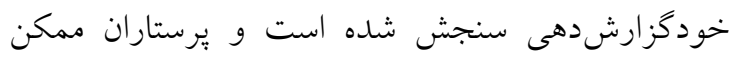

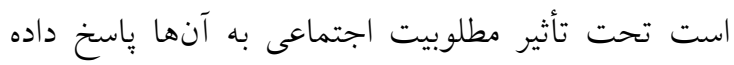

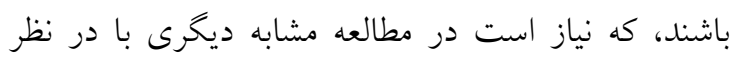

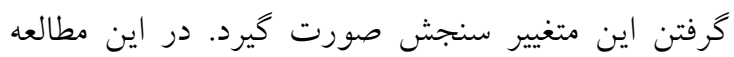
توصيف شايستخى و خودكارآمدى برستاران اورزانس

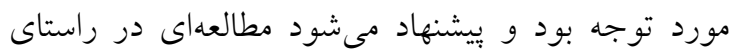

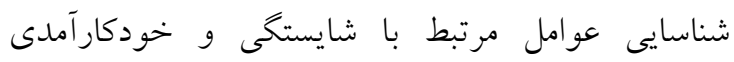

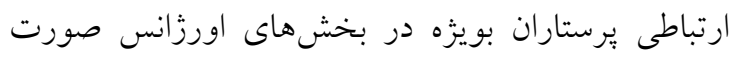

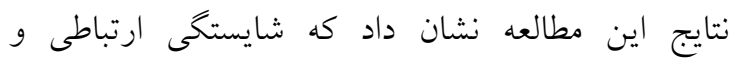

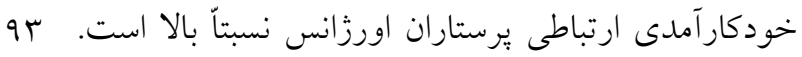
هر جند با توجه به نقش اين افراد در خط مقدم سازمان

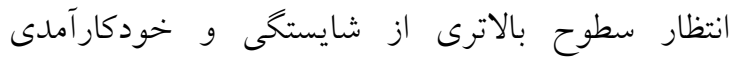

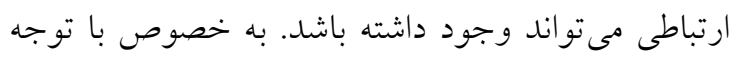




$$
\begin{aligned}
& \text { شركت كننده در اين مطالعه و تمام كسانى كه ما را در } \\
& \text { انجام اين ئزوهش يارى نمودهاند تشكر نمايند. }
\end{aligned}
$$

\section{References}

1. Mehrabian F, Rahbar Taramsari M, Keshavars Mohamadian S. Quality of services in training and medical emergency centers. Journal of Guilan University of Medical Sciences. 2014;23(89):1521. [Persian]

2. Ahmadi O, Talkhoncheh MG, Naieni AP, Tansaz Z. Quality of Nursing Care and Documentation with Overcrowding in Emergency Department. Iranian Journal of Emergency Medicine. 2016;3(2):53-7. [Persian]

3. Latham LP, Ackroyd-Stolarz S. Emergency department utilization by older adults: a descriptive study. Canad Geriatr J. 2014;17(4):118.

4. Ezenkwele UA, Roodsari GS. Cultural competencies in emergency medicine: caring for MuslimAmerican patients from the Middle East. J Emerg Medic. 2013;45(2):168-74.

5. Martin JS, Ummenhofer W, Manser T, Spirig R. Interprofessional collaboration among nurses and physicians: making a difference in patient outcome. Swiss medical weekly. 2010;140(3536).

6. Park NK, Lee H, Lee T, Park JS. Correlations among emotional labor, servant leadership, and communication competence in hospital nurses. Korean J Occup Health Nurs. 2015;24(2):57-66.

7. Yu S, Ko Y. Communication competency as a mediator in the self-leadership to job performance relationship. Collegian. 2017;24(5):421-5.

8. Zhu B, Chen CR, Shi ZY, Liang HX, Liu B. Mediating effect of self-efficacy in relationship between emotional intelligence and clinical communication competency of nurses. Int J Nurs Sci. 2016;3(2):162-8.

9. Munroe B, Curtis K, Murphy M, Strachan L, Buckley T. HIRAID: An evidence-informed emergency nursing assessment framework. Aust Emerg Nurs J. 2015;18(2):83-97.

10. Byrne S, Small V, McDaid F, Forde M, Geary U. A new era for emergency care services in Ireland. Emergency Nurse. 2012;20(5):18.

11. Hernández-Padilla JM, Cortés-Rodríguez AE, Granero-Molina J, Fernández-Sola C, CorreaCasado M, Fernández-Medina IM, López-Rodríguez MM. Design and psychometric evaluation of the 'clinical communication self-efficacy toolkit'. Int $J$ Environ Res Public Health. 2019;16(22):4534.

12. Conner M. Self-efficacy, stress, and social support in retention of student registered nurse anesthetists. AANA journal. 2015;83(2):133-8.

13. Bong YS, So HS, You HS. A study on the relationship between job stress, self-efficacy and job satisfaction in nurses. J Korean Acad Nurs Admin. 2009;15(3):425-33.

14. Haghani F, Asgari F, Zare S, Mahjoob-Moadab H. Correlation between self-efficacy and clinical performance of the internship nursing students. Research in medical education. 2013;5(1):22-30. [Persian]

15. Caruso R, Pittella F, Zaghini F, Fida R, Sili A. Development and validation of the nursing profession self-efficacy scale. Int Nurs Rev. 2016;63(3):455-64.

16. Shorey S, Kowitlawakul Y, Devi MK, Chen HC, Soong SK, Ang E. Blended learning pedagogy designed for communication module among undergraduate nursing students: A quasiexperimental study. Nurse Educ Today. 2018;61:120-6.

17. Townsend-Gervis $\mathrm{M}$, Cornell $\mathrm{P}$, Vardaman JM. Interdisciplinary rounds and structured communication reduce re-admissions and improve some patient outcomes. West J Nurs Res. 2014;36(7):917-28.

18. Gausvik C, Lautar A, Miller L, Pallerla H, Schlaudecker J. Structured nursing communication on interdisciplinary acute care teams improves perceptions of safety, efficiency, understanding of care plan and teamwork as well as job satisfaction. J Multidiscipl Health Care. 2015;8:33.

19. Park S. Influences of Professional Autonomy, Communication Competency on Job Satisfaction of Psychiatric Nurses. J Korean Acad Soc Home Hั้ealth Care Nurs. 2018;25(3):232-9. 
20. Cheraghi F, Sanahmadi A, Soltanian A, Sadeghi A. The Ssurvey of Nurses' Communication Skills with Mothers and Hospitalized Children During Nursing Cares in Children Wards. Avicenna Journal of Nursing and Midwifery Care. 2016;24(3):193-200. [Persian]

21. Wloszczak-Szubzda A, Jarosz MJ. Professional communication competences of nurses. Ann Agricult Environm Medic. 2012;19(3):601-7.

22. Jouzi M, Vanaki Z, Mohammadi E. Factors affecting the communication competence in Iranian nursing students: A qualitative study. Iranian Red Crescent Medical Journal. 2015;17(3):e19660. [Persian]

23. Wiemann JM. Explication and test of a model of communicative competence. Human communication research. 1977;3(3):195-213.

24. Axboe MK, Christensen KS, Kofoed PE, Ammentorp J. Development and validation of a selfefficacy questionnaire (SE-12) measuring the clinical communication skills of health care professionals. BMC medical education. 2016 Dec;16(1):272.

25. Kim MO. Study on self-efficacy, communication competency, critical thinking disposition and clinical performance ability of nursing students. J Korea Acad Indus Coop Soc. 2016;17(6):60917.

26. Shafipour V, Mohammad E, Ahmadi F. Barriers to nurse-patient communication in cardiac surgery wards: a qualitative study. Global Journal of Health Science. 2014;6(6):234-244.

27. Ravanipour M, Ahmadiani A, Yazdanpanah A, Soltanian A. Assessing the relationship between self-efficacy and clinical decision-making in hospital nurse. Avicenna Journal of Nursing and Midwifery Care. 2016;23(4):77-86. [Persian] 